UNIVERSIDADE DE BRASÍLIA

Centro de Excelência em Turismo

Pós-graduação Lato Sensu

Curso de Especialização em Turismo e Desenvolvimento Econômico

\title{
ECOTURISMO, POLÍTICAS PÚBLICAS E DESIGUALDADE SOCIAL
}

João Paulo Dantas de Morais

Iara L. G. Brasileiro (Dra)

Brasília - 2008 


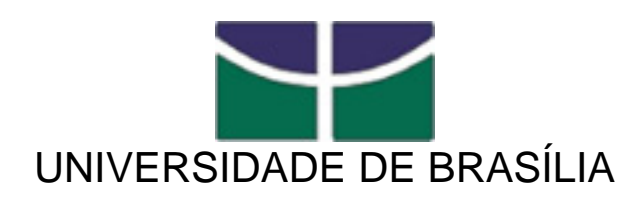

Centro de Excelência em Turismo

Pós-graduação Lato Sensu

Curso de Especialização em Turismo e Desenvolvimento Econômico

\section{ECOTURISMO, POLÍTICAS PÚBLICAS E DESIGUALDADE SOCIAL}

João Paulo Dantas de Morais

Iara L. G. Brasileiro (Dra)

Monografia apresentada ao Centro de Excelência em Turismo - CET, da Universidade de Brasília - UnB, como requisito parcial à obtenção do gral de Especialista em Turismo e Desenvolvimento Econômico. 
Morais, João Paulo.

Ecoturismo, Políticas Públicas e Desigualdade Social / João Paulo Morais. - Brasília, 2008.

Monografia (especialização) - Universidade de Brasília, Centro de Excelência em Turismo, 2008.

Orientador(a): Iara L. G. Brasileiro

1. Ecoturismo. 2. Políticas Públicas. 3. Desigualdade Social. I. Título. 


\section{UNIVERSIDADE DE BRASÍLIA}

Centro de Excelência em Turismo

Pós-graduação Lato Sensu

Curso de Especialização em Turismo e Desenvolvimento Econômico

João Paulo Dantas de Morais

Aprovado por:

Professora orientadora: Iara L. G. Brasileiro

Professor:

Professor:

Brasília, 10 de março de 2008. 


\section{DEDICATÓRIA}

Dedico esta monografia à minha família. 


\section{AGRADECIMENTOS}

Agradeço à minha orientadora, lara Brasileira, por sua ajuda na realização dessa monografia.

A minha namorada, Juliana, pela paciência, compreensão e amor dedicados a mim.

E aos meus colegas de classe, pela troca de conhecimentos e experiências. 


\section{RESUMO}

Esta monografia teve como objetivo principal identificara diminuição da pobreza no Brasil, com a implementação do ecoturismo em Unidades de Conservação UC. Foi estudado o Sistema Nacional de Unidade de Conservação - SNUC, juntamente com as políticas públicas do ecoturismo no combate a desigualdade social, o turismo e ecoturismo como fonte de crescimento econômico e sua aplicação no PARNAMAR. Observou-se que a aplicabilidade das políticas públicas do ecoturismo em Fernando de Noronha é evidente, pois o governo juntamente com a iniciativa privada e organizações não governamentais fazem um trabalho de sustentabilidade promovendo benefícios à comunidade local.

Palavras-chave: ecoturismo, políticas públicas, desigualdade social. 


\begin{abstract}
This monograph had as main objective it identifies reduction of the poverty in Brazil, with the implementation of the ecotourism in Units of Conservation - UC. The National System of Unit of Conservation - SNUC was studied, together with the public politics of the ecotourism in the combat of the social inquality, the tourism and ecotourism as source of economic growth and its application in the PARNAMAR. The government with the private initiative was observed together that the applicability of the public politics of the ecotourism in Fernando de Noronha is evident, therefore and not governmental organizations make a sustenance work promoting benefits to the local community.
\end{abstract}

Key- Word: ecotourism, public politics, social inquality. 


\section{LISTA DE ABREVIATURAS E SIGLAS}

CDB - Convenção sobre a Diversidade Biológica

$\mathrm{Cl}$ - Conservation Internacional

CIMA - Comissão Interministerial para Preparação da Conferência das Nações

Unidas sobre Meio Ambiente e Desenvolvimento

EMBRATUR - Instituto Brasileira de Turismo

IBAMA - Instituto Brasileiro de Meio Ambiente de dos Recursos Naturais Renováveis

IBDF - Instituto Brasileiro de Desenvolvimento Florestal

IUCN - União Internacional para Conservação de Natureza e seus Recursos

MMA - Ministério do Meio Ambiente

MTur - Ministério do Turismo

OMT - Organização Mundial do Turismo

PARNAMAR - Parque Nacional Marinho de Fernando de Noronha

SNUC - Sistema Nacional de Unidade de Conservação

UC - Unidade de Conservação

VAB - Valor Agregado Bruto 


\section{SUMÁRIO}

Introdução

1. Análise do Sistema Nacional de Unidade de Conservação para o Ecoturismo no Brasil.

1.1. O Sistema Nacional de Unidade de Conservação 14

1.2. Patrimônio Natural Brasileiro 16

1.2.1. Floresta Amazônica 17

1.2.2. Cerrado 18

1.2.3. Caatinga 19

1.2.4. Mata Atlântida 20

1.2.5. Pantanal 21

1.2.6. Mata das Araucárias 22

1.2.7. Campos do Sul 22

1.2.8. Zonas Costeiras 23

1.2.9. Mangues 24

1.3. Importância de uma Unidade de Conservação e sua definição25

1.4. Unidades de Proteção Integral - Parques Nacionais

2. Políticas Públicas do Ecoturismo no Combate a Desigualdade Social.

2.1. Diretrizes de Ecoturismo para uma Política Pública Contra a Desigualdade Social 28

2.2. Diretrizes para o Combate a Desigualdade Social 30

2.3. Envolvimento Comunitário 31

2.4. Capacitação 32

2.5. Infra-estrutura 33

3. História do Turismo e Ecoturismo no Brasil.

3.1. Turismo

$\begin{array}{ll}\text { 3.2. Ecoturismo } & 37\end{array}$ 
4. Ecoturismo e Combate a Desigualdade Social 39

4.1. Parque Nacional Marinho Fernando de Noronha 40

4.2. Atividades realizadas em Fernando de Noronha 40

4.3.Ecoturismo no Combate a Desigualdade Social 43

Considerações Finais $\quad 45$

$\begin{array}{ll}\text { Referências Bibliográficas } & 47\end{array}$ 


\section{Introdução}

No ano de 2004, em uma ação conjunta com o Ministério do Turismo - MTur e Ministério do Meio Ambiente - MMA, foram realizadas cinco oficinas no Brasil, nas regiões Centro-Oeste, Sul, Norte, Nordeste e Sudeste denominadas de Diálogos das Diretrizes para o Ecoturismo, tendo como principal objetivo a análise do documento intitulado Diretrizes para uma Política Nacional de Ecoturismo, de 1994.

$\mathrm{Na}$ realização deste trabalho houve a análise do tema e dos materiais utilizados, como as Diretrizes para Política Nacional de Ecoturismo (Brasil, 1994), o Relatório Preliminar: Oficinas Diálogos para as Diretrizes de Ecoturismo - regiões: Norte, Nordeste, Centro-oeste, Sul e Sudeste. (Brasil, 2004)

Juntamente com estes documentos oficiais do governo federal foram utilizadas também diversas referências bibliográficas, sobre políticas públicas e conceitos relacionados ao ecoturismo e turismo, como também o tema desigualdade social.

Desta forma, foram propostos quatro capítulos para o trabalho. No primeiro capítulo foi feita uma análise sobre o Sistema Nacional de Unidade de Conservação - SNUC, que tem como principal objetivo definir o que são as normas para a utilização das Unidades de Conservação - UC, no Brasil, e uma pequena contextualização dos biomas existentes no Brasil e as principais localidades para a prática do ecoturismo.

Em seguida, no capítulo dois foram introduzidos no trabalho algumas das políticas públicas do ecoturismo para o combate à desigualdade social, que são: envolvimento comunitário, capacitação e infra-estrutura. Por serem de extrema importância para as comunidades carentes.

Assim sendo, no capítulo três observou-se a necessidade de abordar o tema turismo e ecoturismo, suas definições, conceitos, contexto histórico e importância para a economia de um país. 
No quarto capítulo abordamos uma Unidade de conservação - UC, referente à categoria de Parque Nacional, que foi o Parque Nacional Marinho de Fernando de Noronha. Neste capítulo iremos analisar o ecoturismo como uma fonte de renda para a comunidade, e como esta diminuindo a desigualdade social na região.

Para a realização da pesquisa foram introduzidos estudos a fim de melhor compreender como as políticas públicas que são as propostas para o desenvolvimento do ecoturismo no Brasil, é a desigualdade social.

O objetivo principal deste trabalho é identificar a diminuição da pobreza no Brasil, com a implementação do ecoturismo em regiões de preservação ambiental. Para isso é necessário que as Políticas Públicas do ecoturismo juntamente com o SNUC, possa se interligar fazendo com que a renda do país aumente com o fluxo de praticantes do ecoturismo e uma significativa diminuição da pobreza que é o foco principal do trabalho.

O ecoturismo é definido como viagem responsável a áreas naturais, com o fim de conservar o meio ambiente e promover o bem estar da comunidade local. 
Capítulo 1 - Análise do Sistema Nacional de Unidade de Conservação para o Ecoturismo no Brasil

\section{1 - O Sistema Nacional de Unidade de Conservação}

Com o acelerado processo de degradação ambiental que marca a nossa sociedade, de consumo excessivo dos recursos naturais, nota-se que áreas de significativo interesse para o equilíbrio ambiental, são necessárias estabelecer territórios que possam melhor preservar amostras significativas dos ecossistemas e biomas.

O interesse pela preservação de áreas naturais pode ser facilmente percebido, mesmo antes da criação do conceito de Unidade de Conservação UC. A União Internacional para Conservação de Natureza e seus Recursos IUCN define Unidades de Conservação como "áreas definidas pelo Poder Público, visando à proteção e a preservação de ecossistemas no seu estado natural e primitivo, onde os recursos naturais são passíveis de um uso indireto sem consumo". (SNUC, 2005)

A primeira UC brasileira foi o Parque Nacional de Itatiaia, criado em 1937. Após a criação do primeiro parque brasileiro foram criados o Parque Nacional de Iguaçu, no Paraná, e o Parque Nacional da Serra dos Órgãos, no Rio de Janeiro, em 1939. (COSTA, 2002, p. 18)

Em 13 de fevereiro de 1948, o decreto legislativo $n^{\circ} 3$, foi aprovado, fazendo vigorar a conservação para proteção da flora, da fauna e das belezas cênicas dos países da América Latina e definindo as categorias de áreas de preservação como Parque Nacional, Reserva Natural, Monumento Natural e Reserva de Região Virgem, sem promover grandes alterações nas categorias de áreas protegidas já existentes no Brasil. (COSTA, 2002, p. 19)

Em 1959, após um intervalo de 20 anos sem criação de novos Parques Nacionais no país, foram criados o Parque Nacional de Aparados da Serra, que abrange os estados do Rio Grande do Sul e Santa Catarina, o Parque Nacional Araguaia, na Ilha do Bananal, entre os estados do Tocantins e Goiás, e o Parque Nacional do Ubajara, no estado do Ceará. (COSTA, 2002, p. 19) 
Em 1967, foi criado o Instituto Brasileiro de Desenvolvimento Florestal, o IBDF, organismo ligado ao Ministério da Agricultura e que por muito tempo foi o grande mentor das Unidades de Conservação do país. (COSTA, 2002, p. 20)

A Constituição do Brasil, promulgada em 1988, declara, no artigo 225 do capítulo VI - Meio Ambiente: "Todos têm direito ao meio ambiente ecologicamente equilibrado, bem de uso comum do povo e essencial à sadia qualidade de vida, impondo-se ao poder público e à coletividade o dever de defendê-lo e preservá-lo para as atuais e futuras gerações." (COSTA, 2002)

A preservação da biodiversidade deve ser encarada de maneira séria e como fator prioritário para o desenvolvimento sustentável de áreas especiais com relevante interesse ecológico, visando resguardar os recursos naturais para o seu devido equilíbrio.

É importante que áreas significativas sejam preservadas para que a riqueza biológica não se perca sob as pás do desenvolvimento. Para tanto é necessário identificar, por meio de critérios científicos, áreas prioritárias para preservação, superando uma fase anterior de criação desorganizada de UC por todo o país. Faltava, no entanto, uma norma consolidada que desse, ao sistema de proteção, lógica e eficácia em seus propósitos. (SNUC, 2005)

Felizmente, após mais de oito anos de tramitação no Congresso Nacional, temos hoje a lei $n^{0} .9985$, sancionada pelo então Presidente da República Fernando Henrique Cardoso, em 18 de julho de 2000 que foi objeto de inúmeros debates e de ampla consulta aos diferentes segmentos da sociedade brasileira. A lei vem consolidar um arcabouço normativo até então deveras confuso, por abrigar inúmeras leis, cada qual dispondo sobre diversas categorias de manejo. (SNUC, 2005)

A atribuição constitucional genérica que concede competência concorrente a todos os entes da federação para a criação de áreas protegidas, de um sistema que Ihe conferisse um mínimo ordenamento. O novo Sistema Nacional de Unidade de Conservação da Natureza - SNUC, uniformizar e consolidar critérios para o estabelecimento e a gestão das áreas protegidas. (SNUC, 2005)

Os instrumentos previstos na lei são fundamentais para 0 planejamento e a implementação de Políticas Nacionais de Áreas Protegidas 
conduzida pelo Ministério do Meio Ambiente - MMA, agora apto a coordenar sistemas, anteriormente estanques, que passam a funcionar de forma integrada, permitindo à União, Estados e Municípios uma ação articulada capaz de dar maior proteção ao Patrimônio Nacional Brasileiro. (SNUC, 2005)

Além da reclassificação das diversas categorias de UC, a lei traz inovações em vários aspectos, sendo relevantes os que dizem respeito: 1 - a participação social na criação e gestão das UC's; 2 - ao justo tratamento das populações tradicionais que habitam as áreas sob proteção, indenizando-as, oferecendo-Ihe alternativas de subsistência ou adaptando seus métodos produtivos ao uso sustentável dos recursos naturais, conforme o caso; 3 - a garantia da alocação adequada de recursos financeiros necessários as unidades, para que, uma vez criadas, possam ser geridas de forma eficaz, atendendo aos objetivos de sua criação; 4 - a regularização fundiária, de forma integrada com as políticas de administração de terras e águas circundantes considerando, assim, as necessidades sociais e econômicas locais. (SNUC, 2005)

A articulação entre os diferentes setores governamentais é primordial para o desenvolvimento ambiental adequado já que as ações passam a ser feitas em conformidade pelos referidos setores.

O Sistema Nacional de Unidade de Conservação é sem dúvida um importantíssimo instrumento regulador e de manutenção das áreas naturais e um instrumento de relevante interesse das comunidades que moram em municípios próximos aos parques nacionais, porém esse é apenas o início do processo de desenvolvimento social nas comunidades carentes. Após esse estágio, cabe a sociedade exigir que o governo o faça de forma apropriada para melhorar a situação de comunidades menos favorecidas.

\section{2 - Patrimônio Natural Brasileiro}

O Brasil tem uma superfície superior a oito milhões de Km. O âmbito dessa extensão continental abrange desde regiões equatorianas ao norte até áreas extra tropicais ao sul, assim como extraordinária diversidade ecológica. (PNE, 1994) 
É um dos paises de maior biodiversidade do planeta Terra. Foi o primeiro signatário da Convenção sobre a Diversidade Biológica - CDB, é considerado também megabiodiverso - paĺs que reúne ao menos $70 \%$ das espécies vegetais e animais do planeta Terra - pela Conservation Internacional - Cl. (IBAMA, 2007)

Apresenta uma imensa dimensão continental, grande variação climática e de relevo. Abriga sete biomas, 49 ecorregioes, já classificadas, e incalculáveis ecossistemas. Abriga também a maior rede hidrográfica existente e uma riquíssima diversidade sociocultural. (IBAMA, 2007)

Assim sendo, o Brasil é um expressivo legado cultural e natural, com a população acolhedora, florestas, cachoeiras e diversos outros atrativos. A imensidão territorial e a diversidade natural fazem do Brasil um país diferenciado com um imenso potencial social e ecoturistico.

Com o desenvolvimento o ecoturismo no país, desperta crescente interesse em investidores, que percebem no Brasil uma capacidade grande de geração de divisas, fazendo com que a comunidade próxima ao local tenha uma circulação de renda própria, gerando emprego para a comunidade.

Os biomas são identificados como associação de espécies dominantes numa determinada condição climática vigente. Os biomas são regiões homogêneas onde interagem vários fatores, mas no qual a relação entre vegetação, clima e solo têm influência principal. (ROSS, 2003, p. 138)

No Brasil existem nove tipos de bioma, divididos nas cinco regiões, abaixo um pouco sobre cada um desses biomas.

\subsection{1 - Floresta Amazônica}

A Floresta Amazônica abrange os estados do Pará, Amazonas, Amapá, Acre, Rondônia e Roraima e está presente também em países vizinhos: Guianas, Suriname, Venezuela, Equador, Peru e Bolívia. No Brasil, ocupa aproximadamente 3,5 milhões de km. (MRE, 2007)

A formação vegetal está dividida em três principais tipos de mata: igapó - inundada permanentemente; várzea - inundada somente nos períodos de cheia e mata de terra-firme - normalmente não é inundada. (COLTEC, 2007) 
O clima quente da Amazônia não apresenta temperaturas extremamente altas nas médias regulares durante o dia e a noite e ao longo de todo o ano. (ROSS, 2003, p. 160)

A Amazônia é o maior bioma existente no Brasil. Sua área apresenta incrível diversidade, possibilitando a prática de inúmeras atividades de ecoturismo, para comunidade uma fonte renda.

\subsection{2 - Cerrado}

A área central do Cerrado está distribuída, principalmente, pelo Planalto Central Brasileiro, nos Estados de Goiás, Tocantins, Mato Grosso, Mato Grosso do Sul, parte de Minas Gerais, Bahia e Distrito Federal. Há outras áreas de Cerrado, chamadas periféricas, que são transições com os biomas Amazônia, Mata Atlântica e Caatinga. (IBAMA, 2007)

O Cerrado típico é constituído por árvores relativamente baixas, até vinte metros, disseminadas em meio a arbustos, subarbustos e uma vegetação baixa constituída, em geral, por gramíneas. Na época seca o risco de incêndios aumenta bastante devido ao tapete rasteiro presente no bioma parecer palha que nas épocas secas, é facilmente queimado. (IBAMA, 2007)

O clima típico da região dos Cerrados é quente, semi-úmido e notadamente sazonal, com verão chuvoso e inverno seco. (BRASIL, 2004)

O Cerrado brasileiro é reconhecido como a savana mais rica do mundo em biodiversidade com a presença de diversos ecossistemas e riquíssima flora. Assim como a flora, a fauna caracteriza-se pela incrível abundância de espécies. (IBAMA, 2007)

A partir da década de 1990, governos e diversos setores organizados da sociedade debatem como conservar o que restou do Cerrado, com a finalidade de buscar tecnologias embasadas no uso adequado dos recursos hídricos, na extração de produtos vegetais nativos, nos criadouros de animais silvestres, no ecoturismo e outras iniciativas que possibilitem um modelo de desenvolvimento sustentável e justo. (IBAMA, 2007)

Observou-se com a interiorização da capital, a agricultura extensiva acarretou em um grande impacto ambiental do Cerrado e esse impacto, 
infelizmente, acompanha os atuais dias. Não possuindo o litoral como atrativo, o bioma é dotado de extraordinário valor para o ecoturismo, apresentando variadas formações naturais, bom clima e numerosas opções para a prática das diversificadas atividades relacionadas, como é o caso dos Parques Nacionais de Brasília e da Chapada dos Veadeiros em Goiás.

\subsection{3 - Caatinga}

O bioma Caatinga é o principal ecossistema existente na Região Nordeste, estendendo-se pelo domínio de climas semi-áridos, ocupa aproximadamente $7 \%$ do território nacional, abrange os estados da Bahia, Ceará, Piauí, Pernambuco, Rio Grande do Norte, Paraíba, Sergipe, Alagoas, Maranhão e Minas Gerais. (IBAMA, 2007)

O termo Caatinga é originário do tupi-guarani e significa mata branca. É um bioma único, pois apesar de estar localizado em área de clima semi-árido, apresenta grande variedade de paisagens e relativa riqueza biológica. A ocorrência de secas estacionais e periódicas estabelece regimes intermitentes aos rios e deixa a vegetação sem folhas. A folhagem das plantas volta a brotar e fica verde nos curtos períodos de chuvas. (IBAMA, 2007)

A Caatinga é dominada por tipos de vegetação com formações vegetais secas, que compõem uma paisagem espinhosa, com estratos compostos por gramíneas, arbustos e árvores de porte baixo ou médio, entre 3 a 7 metros de altura. (IBAMA, 2007)

A extração de madeira, para as carvoarias, para a formação da monocultura da cana-de-açúcar e a pecuária nas grandes propriedades, ou seja, os latifúndios deram origem à exploração econômica desordenada do bioma. (IBAMA, 2007)

Percebe-se que o bioma Caatinga oferece um clima de pouca chuva e belas paisagens, o que é imprescindível para a realização de práticas do ecoturismo. A adequada forma de incremento do ecoturismo nas áreas da Caatinga pode motivar o impulso econômico, juntamente com a melhoria da qualidade de vida da população local, em questões sócio ambientais, podendo 
ser um importante instrumento de busca e desenvolvimento de soluções para as severas secas.

O Parque Nacional de Sete Cidades ao norte do Estado do Piauí apresenta relevante patrimônio arqueológico agregando valores ao patrimônio natural da Caatinga.

\subsubsection{Mata Atlântica}

O primeiro nome dado pelos portugueses à extensa muralha verde que separava o mar das terras interiores foi Mata Atlântica. Hoje esse é um nome genérico com que popularmente é conhecida uma grande variedade de matas tropicais úmidas que ocorrem nas regiões costeiras do Brasil. (CONTI, 2003, p. 171)

A Mata Atlântica originalmente percorria o litoral brasileiro de ponta a ponta. Estendia-se do Rio Grande do Norte ao Rio Grande do Sul, e ocupava uma área de 1,3 milhões de quilômetros quadrados. Tratava-se da segunda maior floresta tropical úmida do Brasil, só comparável à Floresta Amazônica. (MACHADO, MARTINS E ROZ, 2007)

Atualmente restam apenas $5 \%$ de sua extensão original. A Mata Atlântica pode ser vista como um mosaico diversificado de ecossistemas em função de diferenças de solo, relevo e características climáticas existentes na ampla área de ocorrência desse bioma no Brasil. (IBAMA, 2007)

Acredita-se que sendo um mosaico diversificado de ecossistemas, a Mata Atlântica é considerada um dos biomas com maior interesse para o ecoturista, já que a diversidade apresentada possibilita a realização de grande quantidade de atividades específicas do ecoturismo em áreas do mesmo bioma.

O Parque Nacional do Superagui é um exemplo de Unidade de Conservação que se encontra em área de Mata Atlântica, mais especificamente no Estado do Paraná. 


\subsubsection{Pantanal}

A Comissão Interministerial para Preparação da Conferência das Nações Unidas sobre Meio Ambiente e Desenvolvimento - CIMA, em 1991, define o Pantanal Matogrossense como "a maior planície de inundação contínua do planeta". Sua localização geográfica é de particular relevância, uma vez que representa o elo entre o Cerrado, no Brasil Central, o Chaco, na Bolívia, e a região Amazônica, ao Norte. (IBAMA, 2007)

Os solos, de modo geral, apresentam limitações à lavoura. Nas planícies pantaneiras sobressaem solos inférteis em áreas úmidas, além de várias outras classes, todos alagáveis, em maior ou menor grau, e de baixa fertilidade. (IBAMA, 2007)

Como área de transição, a região do Pantanal ostenta um mosaico de ecossistemas terrestres, com afinidades, sobretudo, com os Cerrados e, em parte, com a Floresta Amazônica, além de ecossistemas aquáticos e semiaquáticos, interdependentes em maior ou menor grau. (IBAMA, 2007)

A planície inundável que forma o Pantanal propriamente dito representa uma das mais importantes áreas úmidas da América do Sul. Esse ambiente, periodicamente inundado, apresenta, grande densidade $\mathrm{e}$ diversidade de fauna e flora. (IBAMA, 2007)

O Pantanal é um bioma muito complexo sendo considerado a maior área alegável do planeta, favorecendo dessa forma a incrível diversidade biológica lá encontrada. Já apresenta um elevado interesse turístico e vários segmentos de atividades do ecoturismo.

Essa alternativa econômica é considerada de baixo impacto ambiental na região. Um interessante exemplo conhecido pelo desenvolvimento sustentável do turismo é Bonito, cidade do Mato Grosso do Sul, que apresenta bons resultados decorrentes deste desenvolvimento.

O Parque Nacional do Pantanal Matogrossense deve ser considerado como uma UC importante para a prática do ecoturismo na área compreendida pelo bioma em questão. 


\subsubsection{Mata de Araucárias}

A Mata das Araucárias, ao contrário da Floresta Amazônica, constitui numa formação aberta, homogênea a única floresta subtropical, ou temperada quente. Essa formação é a floresta mais desmatada em nosso país devido ao grande desenvolvimento agrícola e industrial. Entretanto, foi a zona pioneira em reflorestamento. (ANTONELI, DOUHI E LOPES, 2007)

As áreas de distribuição das florestas de araucárias compreendem as terras altas dos planaltos e serras do Sul do Brasil, nos Estados do Rio Grande do Sul, Santa Catarina, Paraná e São Paulo. No Rio de Janeiro e em Minas Gerais há uma pequena penetração dessas florestas frias. (CONTI, 2003, p. 184)

Acredita-se que mesmo sendo um dos menores biomas brasileiros, a Mata de Araucárias apresenta uma área com incomparável beleza cênica e com um conhecido litoral. Um exemplo é Florianópolis e seu entorno que apresentam lindas praias e atraem a atenção dos ecoturistas, com trilhas, cachoeiras, escaladas e vôo livre, todos acompanhados por paisagens maravilhosas. A canoagem, o mergulho e a caça submarina também são praticados em áreas oferecidas pelo referido bioma.

Os Parques Nacionais dos Aparados da Serra e Serra Geral apresentam áreas no Estado do Rio Grande do Sul e Santa Catarina e fazem parte em algumas áreas, do bioma da Mata de Araucárias.

\subsubsection{Campos do Sul}

De maneira genérica, os campos da região Sul do Brasil são denominados como pampa termo de origem indígena para região plana. Esta denominação, no entanto, corresponde somente a um dos tipos de campo, mais encontrado ao sul do Estado do Rio Grande do Sul, atingindo o Uruguai e a Argentina. (IBAMA, 2007) 
Os campos, em geral, são formações edáficas, do próprio solo e não climáticas. A pressão do pastoreio e a prática do fogo não permitem o estabelecimento da vegetação de arbustos, como se verifica em vários trechos da área de distribuição dos Campos do Sul. (IBAMA, 2007)

A vocação da região está na pecuária de corte. As técnicas de manejo adotadas, porém, não são adequadas para as condições desses campos, e a prática artesanal do fogo ainda não é bem conhecida em todas as suas conseqüências. As pastagens são, em sua maioria, utilizadas sem grandes preocupações com a recuperação e a manutenção da vegetação. Os campos naturais no Rio Grande do Sul são geralmente explorados sob pastoreio contínuo e extensivo. (IBAMA, 2007)

O ecoturismo na região dos pampas pode ser estimulado de forma a desenvolver a consciência da sociedade local sobre importante preservação ambiental, visando proteger as espécies em extinção que habitam esse bioma, assim como utilizando mais racionalmente o espaço e contribuindo para o controle das queimadas, que causam grandes impactos ambientais.

A Estação Ecológica do Taim e parte do Parque Nacional de Aparados da Serra contemplam as Unidades de Conservação do bioma.

\subsubsection{Zonas Costeiras}

O Brasil apresenta uma extensa área costeira. O mar representa uma importante fonte de alimento, emprego e energia. Sendo assim, as questões relacionadas aos oceanos assumem importância fundamental para o povo brasileiro. Os recursos estão diretamente associados com a sustentabilidade exploratória dos recursos pesqueiros por meio da pesca artesanal, do turismo e uma das manifestações culturais das comunidades tradicionais da orla marítima, como o folclore, tradições, estilo de vida. Entretanto, a vulnerabilidade desse patrimônio sócio-ambiental está ameaçada pela falta de planejamento na ocupação e nas ações das atividades humanas na zona costeira. (AMBIENTE, 2007) 
$\mathrm{Na}$ costa brasileira ocorrem diversos tipos de habitat, formando uma enorme diversidade de ecossistemas. Além das praias arenosas amplamente utilizadas pelo turismo, destacam-se inúmeros santuários e lagoas costeiras, praias, manguezais, recifes de coral, bancos de algas, plataformas arenosas, dunas, ilhas costeiras e ilhas oceânicas. (AMBIENTE, 2007)

Verifica-se que o ecoturismo também pode ser explorado de forma sustentável para auxiliar o equilíbrio ecológico do bioma, já que as áreas são frágeis e necessitam de um desenvolvimento adequado. As Zonas Costeiras têm imensa influência na decisão de um destino turístico por turistas e ecoturistas em virtude do apelo litorâneo que é na maioria das vezes o principal atrativo de uma viagem.

Os Parques Nacionais que se destacam nesse bioma são: Parque Marinho de Fernando de Noronha e Abrolhos.

\subsubsection{Mangues}

O Brasil tem uma das maiores extensões de manguezais do mundo. Estes ocorrem ao longo do litoral Sudeste-Sul brasileiro, margeando estuários, lagunas e enseadas, desde o Cabo Orange no Amapá até o Município de Laguna, em Santa Catarina. Os mangues abrangem uma superfície total de mais de $10.000 \mathrm{~km}^{2}$, a grande maioria na Costa Norte. O Estado de São Paulo tem mais de $240 \mathrm{~km}^{2}$ de manguezal. (AMBIENTE, 2007)

O mangue é um ecossistema particular, que se estabelece nas regiões tropicais de todo o globo. Origina-se a partir do encontro das águas doce e salgada. Este ambiente apresenta água com salinidade variável, sendo exclusivo das regiões costeiras. (AMBIENTE, 2007)

No Brasil, os mangues são protegidos por legislação federal, devido à importância que representam para o ambiente marinho. São fundamentais para a procriação e o crescimento dos filhotes de vários animais, como rota migratória de aves e alimentação de peixes. Além disso, colaboram para o enriquecimento das águas marinhas com sais nutrientes e matéria orgânica. (AMBIENTE, 2007) 
Por estarem localizados no litoral, também podem ser aproveitados para o ecoturismo e desenvolvimento de uma comunidade que faz do mangue sua principal fonte de renda, utilizando os instrumentos benéficos que são desenvolvidos quando de forma correta, fortalecendo o frágil ecossistema.

A Estação Ecológica de Carijós foi criada na tentativa de conter a degradação dos manguezais e localiza-se em território catarinense.

Percebe-se que o quadro atual de degradação da natureza em todo o mundo e no Brasil nos faz refletir sobre ações imediatas que tangem o tema da preservação do meio ambiente para a melhoria da qualidade de vida na Terra. As Unidades de Conservação refletem essa necessidade atual de preservação da natureza, já que são realidades em todo o mundo.

\subsection{Importância de uma Unidade de Conservação e sua definição}

O ecoturismo pode ser desenvolvido em ambientes naturais equilibrados, como as unidades de conservação, a importância dessas UC's é de extrema importância para desenvolver um município economicamente, levando capacitação e renda para pessoas moradoras do local.

As Unidades de Conservação protegem áreas importantes ambientalmente e em muitos casos permitem seu uso de forma sustentável, caracterizando essas áreas como de total interesse para a atividade. Dessa forma ficou evidente a importância destas UC's para o desenvolvimento sustentável do ecoturismo e o combate a desigualdade social existente no Brasil.

O interesse do governo em fazer políticas para o ecoturismo e contra a desigualdade social tende a andar juntas, pois implementando o ecoturismo em áreas de preservação natural faz com que as populações residentes nessas áreas aumentem sua renda gerando benefícios como: fome, emprego, saúde.

O SNUC tem os seguintes objetivos: 
1 - Contribuir para a manutenção da diversidade biológica e dos recursos genéticos no território Nacional e nas águas jurisdicionais;

2 - Proteger as espécies ameaçadas de extinção em âmbito regional e nacional;

3 - Contribuir para a preservação e a restauração da diversidade de ecossistemas naturais;

4 - Promover o desenvolvimento sustentável a partir dos recursos naturais;

5 - Promover a utilização dos princípios e práticas de conservação da natureza no processo de desenvolvimento;

6 - Proteger paisagens naturais e pouco alteradas de notável beleza cênica;

7 - Proteger as características relevantes da natureza geológica, geomorfológica, espeleológica, arqueológica, paleontológica e cultural;

8 - Proteger e recuperar recursos hídricos e edáficos;

9 - Recuperar ou restaurar ecossistemas degradados;

10 - Proporcionar meios e incentivos para atividades de pesquisa científica, estudos e monitoramento ambiental;

11 - Valorizar econômica e socialmente a diversidade biológica;

12 - Favorecer condições e promover a educação e interpretação ambiental, a recreação em contato com a natureza e o turismo ecológico;

13 - Proteger os recursos naturais necessários para a subsistência de populações tradicionais, respeitando e valorizando seu conhecimento e sua cultura e promovendo-as social e economicamente. (SNUC, 2000, p. 10)

As Unidades de Conservação resguardam áreas de relevante interesse ecológico que é de fundamental importância na minimização dos impactos ambientais. O meio ambiente é o objeto do ecoturismo, dessa forma são importantíssimas ao desenvolvimento sustentável da atividade já que promovem o equilíbrio ambiental promovendo a devida integração com a atividade proporcionando uma renda melhor para essas populações que moram nesses ambientes.

\section{4 - Unidades de Proteção Integral - Parques Nacionais}

O objetivo básico das unidades de proteção integral é preservar a natureza, sendo admitido apenas o uso indireto dos seus recursos naturais, com exceção dos casos previstos na Lei. O grupo é composto pelas seguintes categorias Estação Ecológica, Reserva Biológica, Parque Nacional, Monumento Natural e Refúgio de Vida Silvestre. (SNUC, 2005, p. 13) 
O Parque Nacional é a categoria que foi escolhida para ser abordado nesta pesquisa, pois tem como objetivo básico a preservação de ecossistemas naturais de grande relevância ecológica e beleza cênica, possibilitando a realização de pesquisas científicas e o desenvolvimento de atividades de educação e interpretação ambiental, de recreação em contato com a natureza e de turismo ecológico, proporcionando emprego e renda para as comunidade carentes. (SNUC, 2005, p. 14)

A categoria de Parque Nacional abrange inúmeras unidades de conservação no Brasil que em muitos casos já fomentam o mercado ecoturístico, como o caso do Parque Nacional Marinho Fernando de Noronha. A visitação e uso de seus recursos naturais de forma sustentável são estimulados e compreendidos pelos visitantes que são ensinados por pessoas que moram na localidade e são capacitadas para fazer esse trabalho de mostrar como funciona a sustentabilidade de áreas preservadas.

Muitos parques funcionam com capacidade de carga estabelecida, pois a falta de planejamento adequado e manutenção acabam propiciando a degradação do meio ambiente. Um exemplo é o Parque Nacional da Chapada dos Veadeiros, no estado de Goiás, que em épocas de alta temporada, fica explícita a poluição dentro de suas limitações, segundo nossa percepção ao longo das viagens realizadas nesta região. 
Capítulo 2 - Políticas Públicas do Ecoturismo no Combate a Desigualdade Social

\section{1 - Diretrizes de Ecoturismo para uma Política Pública Contra a Desigualdade Social}

Neste capítulo serão abordadas as propostas que as Políticas Públicas do ecoturismo vêm apresentando para os diálogos que devem existir entre os principais atores do setor, entre o poder público, setor privado, organizações não governamentais, comunidades, instituições de ensino e pesquisa, juntamente com a análise dos seus respectivos papéis e responsabilidades.

Devido a crescente demanda pelo segmento ecoturístico, e a total ausência de consenso sobre sua conceituação, é necessário o desenvolvimento de critérios, regulamentações e incentivos para orientar empresários, investidores e o próprio governo, no estímulo e no uso do potencial das belezas naturais e valores culturais disponíveis, ao mesmo tempo promovendo sua conservação.

O período posterior à Segunda Guerra Mundial marca a origem das Políticas Públicas do turismo, que coincide com a regulação do trabalho, na limitação de seu tempo, as férias remuneradas, a aposentadoria, bem como a evolução dos transportes, a comunicação e outras conquistas importantes da sociedade moderna. (PEREIRA, 1999, p. 9)

Observa-se, que a partir deste período, há uma maior conscientização por parte governamental em relação à importância do fenômeno do turismo, como instrumento de crescimento econômico e desenvolvimento social.

Uma vez que esta atividade tem um efeito multiplicador sobre diversos segmentos econômicos, sociais e culturais, requer investimentos prévios em infra-estrutura e maior participação do Estado na formulação de Políticas Públicas de turismo, fundamental para controlar o crescimento 
desordenado da atividade, motivado, unicamente, pelo lucro por parte das empresas. (PEREIRA, 1999, p. 10)

Nota-se que durante muito tempo os responsáveis pela criação das Políticas Públicas, ficaram ausentes em termos de participação nessas criações. Somente em 1977, ou seja, onze anos depois da criação da EMBRATUR, é que foi publicado um documento contendo a Política Nacional de Turismo. (PEREIRA, 1999, p. 15)

É importante ressaltar que, as Políticas Públicas de turismo começam a ter importante espaço no cenário político nacional, mesmo que não fossem de extrema complexidade e compostas por diretrizes e estratégias direcionadas ao setor.

O período de transição do regime militar, com a instauração da Nova República, também é um marco importante na história das Políticas Públicas de turismo no Brasil. Já eram constatadas, neste período, novas funções e competências de natureza jurídica e política entre os órgãos normativos responsáveis em executar a política de turismo no país. (PEREIRA, 1999, p. 15)

Entretanto, observa-se que, para alcançar uma política integrada do turismo em âmbito municipal, estadual e federal, é de extrema importância a participação dos principais atores envolvidos diretamente, ou mesmo daqueles que são interessados no processo de desenvolvimento do turismo em suas localidades ou regiões brasileiras, nos setores públicos, iniciativa privada, nas organizações não governamentais, instituições de ensino e pesquisa e sociedade civil organizada.

Por isso é de extrema importância a participação de todos na realização das Políticas Publicas para o combate a desigualdade social no Brasil. No item 2.2 iremos ver algumas das diretrizes de eco turismo, para tentar diminuir com a desigualdade social no Brasil. 


\section{2 - Diretrizes para o Combate à Desigualdade Social}

A política de turismo precisa ser o elo integrador entre a esfera governamental, representada pelos segmentos oficiais do sistema, e os beneficiários dessa política para a sociedade. (PEREIRA, 1999, p. 12)

Analisando este conceito, verifica-se que as políticas de turismo, quando elaboradas de forma ampla, tornam-se importantes instrumentos de interface que facilitam e norteiam as relações entre todos os atores que compõem a atividade como um todo.

Segundo Cruz (2002, p. 30), a Política Pública de turismo deveria ser um documento que reunisse o pensamento dos poderes públicos, em âmbito local, estadual e nacional, com relação à organização do setor turismo em um dado território. Objetivos, metas, diretrizes e estratégias devem estar claramente expostas em um documento desta natureza.

A Organização Mundial do Turismo - OMT expressa a importância da Política Pública para o bom desempenho do setor do turismo no texto que se segue abaixo.

[...] no caso da política pública turística, as funções do setor são de grande importância, uma vez que, em comparação a outras políticas setoriais, se caracteriza por uma grande complexidade que vem determinada por duas circunstâncias fundamentais: a variedade de sub-setores que formam o que se conhece por setor turístico - restaurantes, alojamentos, agências de viagem etc. - que amplia a tomada de decisões gerais, pois cada sub-setor tem problemas diferentes e específicos; e a heterogeneidade do setor que gera maiores problemas para as administrações públicas em função da coordenação do mercado. (OMT, 2001 apud CRUZ, 2002, p. 30)

Assim, as Políticas Públicas de ecoturismo podem ser consideradas um importante instrumento no processo de planejamento para o desenvolvimento da atividade principalmente, para se garantir um maior aproveitamento de seus benefícios aos atores envolvidos e principalmente no combate a desigualdade que existe no Brasil. 


\section{3 - Envolvimento Comunitário}

O envolvimento comunitário na criação de Políticas Publicas é de extrema importância, pois é a comunidade que vai aceitar ou não as normas que estão sendo proposta.

O quadro abaixo apresenta o conjunto de ações para as estratégias de Envolvimento Comunitário que fazem parte da Tabela de Diretrizes do Eco turismo do ano de 2004, que pode ter um papel importante no combate a desigualdade no Brasil, que em seguida será analisada:

- Promover a adequação das potencialidades da comunidade com as demandas do eco turismo;

- Apoiar a comunidade nas suas iniciativas de engajamento e capacitação na atividade de eco turismo;

- Fomentar a participação das lideranças comunitárias nas etapas de planejamento e realinhamento de projetos ecoturistico;

- Desenvolver campanhas informativas sobre o turismo e suas possibilidades econômicas junto à comunidade;

- Promover a municipalização das atividades de ecoturismo, incentivando o seu desenvolvimento.

Quadro I - Seleção das ações de envolvimento comunitário. (BRASIL, 2004)

A exclusão comunitária na criação de empreendimentos e no planejamento dos mesmos é um fato que ocorre atualmente em diferentes destinos ecoturisticos brasileiros.

Isto é considerado como uma falta de respeito com a população que reside no local, pois na maioria dos casos, não há interesse por parte de integrantes da iniciativa privada em incluir a comunidade no processo, já que seu foco é principalmente o sucesso econômico dos empreendimentos. A inserção comunitária é encarada, por muitos, como uma perda de tempo por não gerar benefícios econômicos.

Este pensamento direciona o ecoturismo a condições degradantes geradoras de impactos ambientais, sociais e econômicos negativos, assim como de uma massa social excluída. 
Sendo assim, a inserção comunitária deve realmente acontecer para que o processo evolutivo do ecoturismo seja bem sucedido. Devem-se adequar as potencialidades locais com a demanda da atividade, ampliar a participação das lideranças comunitárias nas etapas de planejamento e de desenvolvimento de projetos ecoturisticos, resgatar os valores culturais da localidade, valorizando o local e atendendo as necessidades humanas, principalmente em relação aos cidadãos das comunidades excluídas.

\section{4 - Capacitação}

O objetivo da diretriz de capacitação é propiciar informações básicas para a identificação de cursos e treinamento dirigidos a membros ou setores de comunidades para fins de atividades de ecoturismo.

Apresenta-se a seguir um quadro com um conjunto de ações selecionadas a partir das estratégias definidas para capacitação, que fazem parte da Tabela de Diretrizes do Ecoturismo do ano de 2004.

- Promover a capacitação de recursos humanos dos setores governamentais, federal, estadual e municipal, na área de ecoturismo;

- Desenvolver campanha de sensibilização nos setores governamentais, federal, estadual e municipal, para as vantagens do ecoturismo como alternativa de desenvolvimento sustentável;

- Fomentar a criação de programa de bolsas de estudos para aperfeiçoamento profissional em ecoturismo;

- Incentivar a inclusão de conteúdos relacionados ao ecoturismo no sistema de ensino, tais como: impactos; estatísticas e comportamento do turista;

- Promover e apoiar cursos e seminários para divulgação de técnicas e métodos de projetos de construção e operação de equipamentos ecoturísticos

- Estimular a realização de cursos técnico-profissionalizantes associados aos serviços do segmento ecoturístico;

- Incentivar e desenvolver programas de capacitação empresarial a nível comunitário, objetivando o aproveitamento de oportunidades negociais derivadas do ecoturismo.

Quadro II - Seleção das ações em capacitação. (BRASIL, 2004)

Ao analisar as ações contidas nas estratégias de capacitação, verificou-se uma enorme dificuldade em selecionar as mais importantes, pois 
observou a importância de todas as ações para se alcançar os objetivos das estratégias de capacitação para o combate a desigualdade social nas UC.

Diante da grande exigência estabelecida pelo mercado turístico, a qualificação profissional contribui e muito para melhor inserir os profissionais no mercado de trabalho e fazendo com que pessoas menos favorecida, possa ter uma oportunidade no mercado turístico.

Através da análise da diretriz de capacitação, nota-se a importância da criação de programas que estimulem o estudo e pesquisa em ecoturismo, a fim de desenvolver a atividade e promover uma maior especialização dos atores envolvidos.

Portanto, com o desenvolvimento do ecoturismo no Brasil, observase que o profissional da atividade deve se adequar aos interesses, hábitos, atitudes e expectativas da demanda, respeitando as capacidades naturais e culturais das comunidades visitadas. Por isso, qualificando as pessoas que vivem em unidades de conservação, a integração com os visitantes vai ser de melhor qualidade por essas pessoas conhecerem a região visitada pelos ecoturistas.

\section{5 - Infra-estrutura}

Aborda-se abaixo, as estratégias de infra-estrutura consideradas fundamentais para o desenvolvimento das atividades do ecoturismo, visando garantir sua sustentabilidade, conforme os princípios expostos no Relatório Final das Oficinas "Diálogos para as Diretrizes de Ecoturismo" - Regiões: Norte, Nordeste, Centro-Oeste, Sul e Sudeste do ano de 2004, que por seguinte serão analisadas.

- Programar sinalização indicativa e educativa nos pólos de desenvolvimento do ecoturismo.

- Incentivar a implantação de infra-estrutura básica nos pólos de ecoturismo.

- Desenvolver alternativas sustentáveis para manutenção e conservação das áreas que desenvolvem o ecoturismo.

- Incentivar o desenvolvimento de infra-estrutura que permita o acesso de portadores de necessidades especiais aos equipamentos ecoturisticos. 
- $\quad$ Promover a terceirização dos serviços e equipamentos turísticos nos pólos de ecoturismo, envolvendo comunidades locais.

Quadro III - Seleção das ações de infra-estrutura. (BRASIL, 2004)

Devido ao crescente número de ecoturistas que procuram por lugares cada vez menos explorados turisticamente e que apresentem melhor qualidade ambiental, principalmente os empreendedores e gestores públicos devem estar atentos não só ao lugar onde irá instalar-se, à forma de receber, hospedar ou conduzir seus clientes, mas principalmente deve proporcionar a maior interação e integração possível entre os visitantes e a natureza, pois são os principais atores que implementam infra-estrutura turística nas localidades proporcionando uma melhor qualidade de vida a comunidade e bem estar dos visitantes.

Pode-se verificar que essas ações podem potencializar os impactos sócio-ambientais positivos e reduzir os negativos advindos da atividade ecoturística, visto que, o ecoturismo se desenvolve em lugares afastados dos grandes centros urbanos, onde as comunidades são pouco populosas e conservam valores e tradições importantes para a manutenção do equilíbrio sócio-econômico.

Portanto, a infra-estrutura é um grande aliado para desenvolver o ecoturismo em regiões onde a natureza é o foco principal dos turistas, proporcionando uma melhor qualidade de vida para as comunidades que residem nessas regiões.

As diretrizes expostas acima, são só algumas que foram estudadas para a construção do trabalho em que o foco principal é o combate à desigualdade social no Brasil.

Capítulo 3 - História do Turismo e Ecoturismo no Brasil 


\section{1 - Turismo}

Segundo a Organização Mundial do Turismo (OMT, 1994), "o turismo compreende as atividades realizadas pelas pessoas durante suas viagens e estadas em lugares diferentes do seu entorno habitual, por um período consecutivo inferior a um ano, por lazer, negócios ou outros".

O turismo faz parte de um universo maior denominado lazer. Entendem-se lazer todas as atividades desenvolvidas fora do sistema produtivo que é o trabalho (TRIGO, 2002, P.11)

Segundo Trigo,

O lazer é uma necessidade e um direito tão legitimo do ser humano quanto a educação, saúde, transporte ou segurança. Portanto, vemos a importância de se desenvolver as Políticas Públicas voltadas para o ecoturismo para tentar diminuir a desigualdade social no Brasil.

Existem várias maneiras de viagens. Pode-se viajar por prazer e diversão, e por outros motivos, como: religião, saúde e eventos esportivos, políticos ou sociais.

O turismo tem passado por uma fase de crescimento no Brasil, especialmente após o plano de estabilização econômica, implementado em 1994 com o início do processo de formação do Mercado Comum (Mercosul) envolvendo Brasil, Argentina, Uruguai e Paraguai.

O turismo nacional vem sendo favorecido em seu desenvolvimento, com a crescente utilização do automóvel e demais meios de transporte, que melhoraram as possibilidades de mobilidade pessoal e coletiva dentro do pais. (SANCHO, 2001)

Com essas melhorias no setor de turismo verifica-se que há uma necessidade de investir nas infra-estruturas básicas das cidades com o objetivo de melhorar ainda mais os deslocamentos e o acesso a informações, dando uma melhor qualidade de vida aos moradores e aos visitantes. 
Pode-se perceber que se vive uma realidade não muito boa, para aqueles que podem fazer as suas viagem de avião. O Brasil vem passando por um momento de crise no chamado caos aéreo, muitas pessoas querendo embarcar para suas viagem e não podendo, pois seus vôos foram cancelados ou atrazados.

Com o lançamento de novos navios de cruzeiro, a construção de novos territórios à exploração turística, observa-se a necessidade de profissionais bem treinados e eficientes para trabalhar na área. (Trigo, 2002, p. 11)

Por isso verifica-se a importância de implementar as Políticas Públicas de capacitação, para desenvolver com as pessoas menos favorecidas uma oportunidade de melhorar sua qualidade de vida e bem estar.

O turismo é considerado geralmente como um tipo de exportação de uma região ou nação até o lugar de destino, no qual gera renda, favorece a criação de empregos, entrada de divisas que ajudam a equilibrar a balança comercial, aumentando os impostos e aquecer a atividade empresarial. (SANCHO, 2001)

Assim sendo, a atividade turística tem uma grande importância na economia devido a sua elevada contribuição para a geração de Valor Agregado Bruto - VAB, na região receptora. (Valor Agregado Bruto é o valor adicionado bruto que equivale aos valores adicionados aos bens e aos serviços nos estágios diferentes do processo produtivo)

A indústria turística caracteriza-se por sua grande complexidade, não só pela grande quantidade de elementos pelos quais é composta, mas, também, pelos diferentes setores econômicos do seu desenvolvimento. (SANCHO, 2001)

Portanto, o turismo é muito importante para o crescimento de qualquer economia, tornando um país, cidade ou município auto sustentável. A diante um seguimento muito importante para a economia do turismo no Brasil. Este seguimento é conhecido como ecoturismo.

\section{2 - Ecoturismo}


O ecoturismo é definido como viagem responsável a áreas naturais, com o fim de conservar o meio ambiente e promover o bem-estar da comunidade local. Esse segmento turístico depende da conservação dos recursos da área natural. A parceria entre as empresas privadas, que organizam experiências de viagem pela natureza, e as entidades governamentais e nãogovernamentais, que são responsáveis pela proteção das áreas naturais pode contribuir para a conscientização sobre a importância do desenvolvimento de programas de ecoturismo visando um equilíbrio entre as atividades. (LINDBERG e HAWKINS, 1995)

A atividade de ecoturismo envolve em outros aspectos, o compromisso responsável com a natureza e um comprometimento social com as comunidades locais envolvidas. Os ecoturistas são em geral amantes da natureza, com uma série de interesses e preocupações de ordem ambiental, econômica e social. Os visitantes devem ter a consciência do comportamento adequado nas áreas de grande importância ambiental, para que os impactos negativos ocorrido durante as atividades sejam minimizados. (LINDBERG e HAWKINS, 1995)

Verificou-se ao longo da atividade realizada no Brasil, houve uma certa necessidade de avaliar a evolução do ecoturismo no Brasil, e os benefícios que pode trazer para as comunidade mais carentes, para que possamos compreender o desenvolvimento da atividade, e realizar uma análise voltada para as políticas publicas do ecoturismo para o combate a desigualdade social.

O ecoturismo é conhecido como uma atividade sustentável, que utiliza a natureza de forma sustentável.

A Organização Mundial de Turismo (OMT, 1997), define o desenvolvimento do turismo sustentável como turismo que "satisfaz as necessidades atuais do turista e da região visitada, enquanto que protege e aumenta oportunidades para o futuro". 
O ecoturismo teve seu crescimento acentuado, no final dos anos oitenta, seguindo a tendência internacional, e a partir daí os primeiros cursos de guia foram oficializados pelo Instituto Brasileiro de Turismo - EMBRATUR. (CARVALHO, 2008)

A partir da década de noventa, principalmente após a Conferência Mundial sobre Meio Ambiente e Sociedade, denominada ECO 92, realizado no Rio de Janeiro o ecoturismo consolidou-se como um mercado que vivencia uma significativa expansão, favorecendo um grande aumento do número de agências e operadoras especializadas, principalmente na região Sudeste e Sul do país. (PIRES, 1998 apud FARIA, 1999)

A partir dos anos 1970 e 1980 o ecoturismo vem se desenvolvendo no Brasil. O ecoturismo é fundamental, como qualquer outra atividade econômica, influenciado pela oferta e procura de seus serviços, essa atividade é uma fonte significativa de benefícios às economias locais.

O ecoturismo é pouco comum entre os viajantes, por ser composto de vários serviços complementares, por exemplo: transporte internacional e local, telecomunicações, segurança pública, operadores de turismo emissivo e receptivo, hospitalidades, guias locais, e atrações de destinos bem administradas. (Nelson, 2004 apud Pereira, 2004, p. 237)

Os atuais Ministérios do Turismo e do Meio Ambiente, incorporando representantes de suas autarquias, a EMBRATUR e o Instituto Brasileiro de Meio Ambiente e dos Recursos Naturais Renováveis - IBAMA, convidaram representantes de destaque que já atuavam com a atividade no Brasil, para participarem de uma Oficina, na cidade de Goiás, em que pudessem estruturar um documento, que seria posteriormente intitulado de Diretrizes para uma Política Nacional de Ecoturismo - 1994.

Este documento foi a base para a criação deste trabalho, por isso notou-se a necessidade de unir as políticas publicas para o ecoturismo para tentar diminuir com a desigualdade social em áreas protegidas. 


\section{Capítulo 4 - Ecoturismo e Combate à Desigualdade Social}

Verificou-se no decorrer desta pesquisa a necessidade da avaliação de exemplos de Unidades de Conservação que explicasse a real aplicabilidade das estratégias propostas nas diretrizes de Políticas Públicas para o ecoturismo no combate a desigualdade social no Brasil.

Assim, optou-se por analisar o Parque Nacional Marinho de Fernando de Noronha, por representar áreas estratégicas, tanto no fator de conservação ambiental como também no fomento da atividade ecoturística.

O Parque Nacional Marinho de Fernando de Noronha representa uma das principais áreas de desenvolvimento do ecoturismo no Brasil, especialmente voltadas às atividades de mergulho, abrangendo em seu contexto um conjunto de significativas áreas de conservação da biodiversidade, como é o caso das áreas marinhas apresentando coerentes propostas de uso sustentável.

Há diante iremos ver, se a população que reside em Fernando de Noronha tem as Políticas Públicas voltada a geração de renda local, já que o arquipélago é todo segmentado para a pratica do turismo e preservação ambiental.

\section{1 - Parque Nacional Marinho de Fernando de Noronha}

A ocupação de Fernando de Noronha, arquipélago descoberto em 1503 pelo navegador Américo Vespúcio, é quase tão antiga quanto a do continente. Por muitos anos o arquipélago foi um ponto estratégico para os navegantes que saíam de Portugal para o Brasil. (NORONHA, 2008)

Depois de várias batalhas entre portugueses, franceses e holandeses, em 1737, sob o domínio de Portugal, foi construído um sistema defensivo com fortificações - o maior construído em sua época. No mesmo século, o arquipélago se transformou em um presídio comum. (NORONHA, 2008) 
Por medida de disciplina, e a fim de evitar as fugas dos presidiários, a vegetação original da ilha foi sendo degradada, influenciando na alteração do clima do arquipélago. Observou-se, porém, que ainda é possível encontrar em alguns locais da ilha um pouco da cobertura vegetal original. (NORONHA, 2008)

Em 1988, o Decreto no 96.693 criou o Parque Nacional Marinho de Fernando de Noronha - PARNAMAR, composto pelo arquipélago de Fernando de Noronha, totalizando $26 \mathrm{~km}^{2}$ de extensão e 11.270 ha de área, que atualmente se encontra gerido pelo IBAMA. No mesmo ano ficou definido junto ao decreto, que a ilha de Fernando de Noronha integra-se ao estado de Pernambuco. (NORONHA, 2008)

O arquipélago é composto por 21 ilhas, formadas a partir de erupções vulcânicas. A identidade da fauna e flora destas ilhas marinhas é classificada como Floresta Estacional Decidual ou Mata Seca, com diferenças entre as estações de seca e de chuva. (MITRAUD, 2001)

Está distante 545 km de Recife, capital do Estado de Pernambuco, 360 km de Natal, capital do Estado do Rio Grande do Norte e 710 km da cidade de Fortaleza, capital do Estado do Ceará. (NORONHA, 2008)

As ilhas do arquipélago apresentam baixa biodiversidade no âmbito terrestre, mas por outro lado, por ser uma área de concentração de correntezas e sedimentos, o arquipélago possui uma grande riqueza de fauna marinha. (MITRAUD, 2001, p. 17)

Após levantamento bibliográfico sobre Noronha, percebe-se que o arquipélago é visto como um dos principais destinos ecoturísticos brasileiros, devido a sua rara beleza, incrível biodiversidade marinha, seu histórico cultural e o comprometimento com a sustentabilidade.

\section{2 - Atividades realizadas em Fernando de Noronha}

A proteção da biodiversidade e a visitação pública em áreas de proteção ambiental são princípios que encabeçam uma sério de objetivos de um Parque Nacional. Um dos fatores que influenciam a criação de um Parque 
Nacional é a existência de atrativos naturais relevantes que possibilitem a integração de atividades de lazer, educação ambiental e sensibilização da população. (MITRAUD, 2001)

Os objetivos do Parque são: proteger as amostras representativas dos ecossistemas terrestre e marinho, preservar a fauna, flora e demais recursos naturais, proporcionar oportunidades controladas de visitação, lazer, educação ambiental e pesquisa científica e contribuir para a preservação dos sítios históricos. (NORONHA, 2008)

Com o crescimento da demanda na procura do ecoturismo no Brasil, as comunidades locais juntamente com o governo, organizações não governamentais e iniciativa privada, viram a necessidade de qualificar as pessoas residentes no arquipélago para a criação de renda local.

Em visita feita ao arquipélago no ano de 2007, observou-se que a maioria das pessoas que vivem na ilha tem o seu emprego ou o seu negócio voltado ao turismo, pois em Fernando de Noronha é proibida prática de pesca.

Muitos dos moradores têm seu emprego ou empreendimentos em pousadas, restaurantes, táxi, guia turístico entre outros. O que se pode notar as política publica voltada para o ecoturismo no combate à desigualdade social é muito importante para o desenvolvimento da localidade, isso se as políticas forem bem implementadas em qualquer região.

Como em todas as Unidades de Conservação a existência de diretrizes é uma realidade, o PARNAMAR de Fernando de Noronha prescreve algumas restrições no controle do impacto ambiental indesejado. Dentro da área do PARNAMAR de Fernando de Noronha são listadas algumas proibições que serão apresentadas no quadro a seguir.

1. pescar ou praticar caça submarina e portar materiais próprios para estas atividades;

2. introduzir animais e plantas; abater, capturar, perseguir e alimentar animais;

3. alterar a vegetação e coletar sementes, raízes e frutos; coletar conchas, corais, pedras, animais vivos ou partes de organismos;

4. mergulhar nas piscinas naturais da baía dos Porcos; descer e mergulhar nas piscinas do Buraco da Raquel e da ponta das Caracas;

5. visitar a praia do Leão e a baía do Sancho, de janeiro a julho, no horário das 18 às $6 \mathrm{~h}$, devido às desovas de tartarugas marinhas (aruanãs); 
6. nadar e mergulhar com os golfinhos, mesmo fora da baía, e parar embarcações nas imediações da baía dos Golfinhos;

7. parar embarcações, com exceção da parada para banho na baía do Sancho;

8. jogar lixo, ponta de cigarros e outros detritos;

9. visitar ilhas, ilhotas e rochedos;

10. acampar, pernoitar e fazer fogo na ilha principal;

11. visitar todas as áreas de uso restrito, sem autorização;

12. caminhar sobre os arrecifes das praias de Atalaia e Leão e da baía Sueste;

13. escrever ou pichar em árvores, rochas ou placas;

14. usar nadadeiras, tênis, protetor solar e similares na praia de Atalaia;

15. acesso de embarcações e veículos não credenciados;

16. praticar mergulho autônomo sem ser através de empresas credenciadas.

Quadro IV - Conjunto de restrições do PANAMAR de Fernando de Noronha. (NORONHA, 2008)

Atualmente existem projetos ecoturísticos sendo realizados no arquipélago e um dos destaques é o Projeto do Golfinho Rotator. A missão deste projetor é utilizar a pesquisa científica sobre os golfinhos, para estudar seu comportamento natural, conservar Fernando de Noronha, promover um programa de Educação Ambiental e fornecer subsídios para o desenvolvimento sustentável da localidade. (GOLFINHOROTATOR, 2008)

Os objetivos do Projeto Golfinho Rotador são:

- Conscientizar a comunidade de Fernando de Noronha para a preservação ambiental, gerando multiplicadores ambientais entre os futuros prestadores de serviços turísticos;

- Capacitar adolescentes ilhéus para trabalharem com ecoturismo;

- Fornecer subsídios ao desenvolvimento de uma sociedade sustentável em F. de Noronha;

- Melhorar a qualidade dos serviços em ecoturismo oferecidos em Fernando de Noronha;

- Estudar a história natural dos golfinhos em Fernando de Noronha;

- Estudar a interação dos golfinhos com o turismo náutico;

- Propor normas de preservação dos golfinhos-rotadores às autoridades competentes;

- Propor e participar de ações que visem a conservação ambiental de Fernando de Noronha.

Quadro V- Objetivos do Projeto Golfinho Rotator. (GOLFINHOROTATOR, 2008)

Verificou-se a necessidade da avaliação um pouco do contexto histórico do ecoturismo em Fernando de Noronha, por ser atualmente um dos mais importantes pólos econômicos da atividade ecoturística no Brasil e pela adoção do planejamento das atividades relacionadas estarem em consonância com a sustentabilidade. 
Com base em dados coletados, discute-se a seguir se as políticas públicas para o ecoturismo, que podem desenvolver uma comunidade economicamente.

\section{3 - Ecoturismo no combate a Desigualdade Social}

Uma das características mais marcantes da economia Brasileira é o seu elevado grau de desigualdade de renda. Uma das formas de reduzir a pobreza e a desigualdade social no Brasil, é discutir o desenvolvimento do ecoturismo com fator de inclusão social.

O ecoturismo como qualquer outra atividade moderna, gera competitividade local e regional. O turista é um cliente e está disposto a consumir, mas quer qualidade em serviços e preços mais justos. Além disso, um dos princípios básicos do ecoturismo é fazer com que as comunidades se beneficiem economicamente da atividade turística.

Nos últimos anos, estamos assistindo a uma importante transformação na distribuição de renda brasileira. Desde 2001, a desigualdade vem caindo consideravelmente. Apesar desta boa noticia, o Brasil é um dos campeões mundiais da alta desigualdade, o que faz da sustentabilidade desta redução uma questão fundamental para o futuro do país. (Barros, 2006)

A queda recente na desigualdade de renda é importante por varias razões. A primeira esta na simples promoção da igualdade de condições. Uma maior renda melhora as condições dos mais pobres para competirem com os demais grupos. Alem disso, sabemos que uma queda na desigualdade significa nada mais do que a redução da distância entre ricos e pobres. (Barros, 2006)

Para se alcançar eficiência, qualidade e diversidade nos produtos oferecidos aos ecoturistas, à comunidade têm que se capacitar, profissionalizando seus serviços e produtos.

Por isso, vimos à importância do ecoturismo como um fator de inclusão social. O ecoturismo é uma atividade que vem crescendo nos últimos 
anos, com o apoio do governo, iniciativa privada e organizações não governamentais, essa atividade pode vim a reduzir mais ainda a distância entre os ricos e pobres no Brasil.

As policias publicas tem como finalidade o direcionamento correto da atividade dentro da comunidade para o aumento da renda, pois fazendo a capacitação, envolvendo a comunidade nas tarefas e com uma boa infraestrutura na localidade, o ecoturismo pode ser implementado em regiões que tenham um bom fluxo de visitação. 


\section{CONSIDERAÇÕES FINAIS}

Este trabalho mostrou o potencial do setor de ecoturismo para reduzir a pobreza e o papel da intervenção governamental na construção desse objetivo.

Vimos à importância do SNUC, para a construção de novas áreas ambientais que possibilitem a prática do ecoturismo. Com o território equivalente a um continente, o Brasil possui vários biomas, com todos tendo uma área preservada, possibilitando a prática do várias atividades, sendo uma delas o ecoturismo.

Com a criação do SNUC, o desenvolvimento do ecoturismo proporcionou uma nova visão sobre a necessidade da preservação do ambiente em que as atividades são realizadas, evidenciando o conceito de sustentabilidade e da desigualdade social.

As políticas públicas do ecoturismo e a desigualdade social foram o tema. Com as políticas de capacitação, envolvimento comunitário e infraestrutura podem-se verificar que são de grande importância no combate a desigualdade social, pois elas fazem com que a comunidade fique atenta para as propostas feitas na região.

Observou-se também a necessidade de discutir o turismo e o ecoturismo, o seu surgimento e desenvolvimento para a economia de qualquer local. Esses foram um dos temas discutidos durante o curso Turismo e Desenvolvimento Econômico.

Foi analisada a pobreza e sua evolução, sendo o exemplo o Parque Nacional Marinho de Fernando de Noronha, tendo como principal atividade a prática do ecoturismo e visitação pública.

Durante a realização desse trabalho pode-se observar que para a diminuição da desigualdade social no Brasil é necessário que o governo, juntamente com a iniciativa privada e as organizações não governamentais estejam sempre interligadas na criação de novas políticas e programas que beneficiem as comunidades carentes. 
Foi visto que as políticas públicas analisadas neste trabalho estão sendo bom implementadas no Parque Nacional Marinho de Fernando de Noronha, possibilitando assim a criação de novas áreas ambientais para o ecoturismo, fazendo com que a renda dos moradores locais aumentem, diminuindo assim a desigualdade social. 


\section{REFERÊNCIAS BIBLIOGRAFICAS}

AMBIENTE Brasil. Biomas. Disponível em:

http://www.ambientebrasil.com.br/composer.php3?base=./natural/index.html\&c

onteudo=./natural/biomas.html . Acesso em: 12 de dezembro de 2007.

AMBIENTE Brasil. Ecossistemas Costeiros. Disponível em: http://www.ambientebrasil.com.br/composer.php3?base=./natural/index.html\&c onteudo=./agua/salgada/ecossistemacosteiro1.html . Acesso em: 16 de dezembro de 2007.

ANTONELI, Valdemir. DOUHI, Nelson. LOPES Jaime Sergio Frajuca. Esboço dos domínios morfoclimáticos e fitogeográficos do Paraná como condicionantes da paisagem. X Simpósio Brasileiro de Geografia Física Aplicada. Departamento de Geografia do Instituto de Geociências da Universidade do Estado do Rio de Janeiro - UERJ. Disponível em: http://geografia.igeo.ueri.br/xsbgfa/cdrom/eixo1/1.1/184/184.htm. Acesso em: 20 de dezembro de 2007.

BRASIL. Ministério do Turismo. Relatório Preliminar das Oficinas "Diálogos para as Diretrizes de Ecoturismo".

BRASIL. Política Nacional de Ecoturismo. Brasília: Ministério do Turismo e Ministério do Meio Ambiente, 1994.

CARVALHO, Vininha F. Origem e desenvolvimento do ecoturismo no Brasil. Net, fev. 2004. Disponível em: http://revistaturismo.cidadeinternet.com.br/artigos/origem-desenv.html. Acesso em 10 de janeiro de 2008.

COltec - Colégio Técnico da Universidade Federal de Minas Gerais. Biomas. Disponível em: http://www.coltec.ufmg.br/ biomas/biomas.htm . Acesso em: 11 de dezembro de 2007.

CONTI, José Bueno, FURLAN, Sueli Ângelo. Geografia: o clima, os solos e a biota. In: Ross, Jurandyr L. Sanches (org). Geografia do Brasil. São Paulo: USP, 2003, pp. $67-198$.

COSTA, Patrícia Côrtes. Ecoturismo. São Paulo: Aleph, 2002. - (Coleção ABC do Turismo) 
CRUZ, Rita de Cássia Ariza de. Políticas Públicas de Turismo no Brasil: Significado, Importância, Interfaces com outras Políticas. In: SOUZA, Maria José (Org.). Políticas Públicas e o Lugar do Turismo. Brasília: Universidade de Brasília; Departamento de Geografia, Ministério do Meio Ambiente, 2002.

Ecoturismo: Praticas para turismo sustentável. / Organização: Sherre Prince Nelson e Ester Maria Pereira. - Manas: Editora Vale / UniNorte, 2004.

GOLFINHOROTATOR. Disponível em: http://www.golfinhorotador.org.brl. Acesso em: 16 de janeiro de 2008.

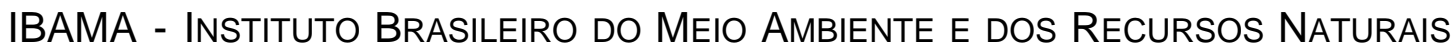
RenOVÁVEIS. Estudos de Representatividade Ecológica nos Biomas Brasileiros. Disponível em: http://www.ibama.gov.br/ecossistemas/estudos.htm. Acesso em 11 de dezembro de 2007.

Introdução ao turismo / direção e redação Amparo Sancho; traduzido por Dolores Martins Rodrigues Córner. -São Paulo: Roca, 2001.

LINDBERG, Kreg, HAWKINS, Donald E. Ecoturismo: Um guia para planejamento e gestão. São Paulo: Editora SENAC, 1995.

MACHADO, Gilmara de Oliveira, MARTINS, Mauro Sérgio, RÓZ, Alessandra Luzia da. Mata Atlântica. Programa Educar. Universidade de São Paulo USP.

Disponível

em:

http://educar.sc.usp.br/licenciatura/trabalhos/mataatl.htm. Acesso em: 23 de dezembro de 2007.

MITRAUD, Sylvia F. Uso recreativo no Parque Nacional Marinho de Fernando de Noronha: um exemplo de planejamento e implementação. Brasília: WWF - Brasil. Vol. 8, 2001, p.100.

NORONHA. Disponível em: http://www.noronha.pe.gov.brl. Acesso em: 12 de janeiro de 2008.

PEREIRA, Cássio Avelino S. Políticas Públicas no Setor de Turismo. Turismo em Análise. São Paulo: 1999. 
PIRES, Paulo dos Santos. A Dimensão Conceitual do Ecoturismo. Turismo Visão e Ação. Santa Catarina: 1998, p.75-91.

SANCHO, Amparo. Definição de Turismo: Introdução ao Turismo. traduzido por Dolores Matin Corner. São Paulo: Roca, 2001.

SNUC - SISTEMA Nacional de Unidades de Conservação da Natureza: lei $\mathrm{n}^{\circ}$ 9.985, 18 de julho de 2000. Brasília: MMA/SBF, 2000. 32p.

Turismo básico / Luiz Gonzaga Godoi Trigo. - 6 ed. Ver. Smpl. São Paulo: Editora SENAC São Paulo, 2002. 